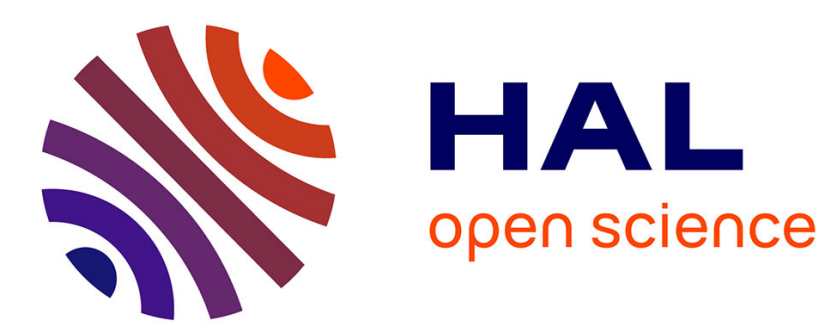

\title{
Neoadjuvant chemoradiation and pancreaticoduodenectomy for initially locally advanced head pancreatic adenocarcinoma
}

O. Turrini, F. Viret, L. Moureau, J. Guiramand, V. Moutardier, B. Lelong, M. Giovannini, J.R. Delpero

\section{To cite this version:}

O. Turrini, F. Viret, L. Moureau, J. Guiramand, V. Moutardier, et al.. Neoadjuvant chemoradiation and pancreaticoduodenectomy for initially locally advanced head pancreatic adenocarcinoma. EJSO

- European Journal of Surgical Oncology, 2009, 35 (12), pp.1306. 10.1016/j.ejso.2009.06.005 . hal00556315

\section{HAL Id: hal-00556315 \\ https://hal.science/hal-00556315}

Submitted on 16 Jan 2011

HAL is a multi-disciplinary open access archive for the deposit and dissemination of scientific research documents, whether they are published or not. The documents may come from teaching and research institutions in France or abroad, or from public or private research centers.
L'archive ouverte pluridisciplinaire HAL, est destinée au dépôt et à la diffusion de documents scientifiques de niveau recherche, publiés ou non, émanant des établissements d'enseignement et de recherche français ou étrangers, des laboratoires publics ou privés. 


\section{Accepted Manuscript}

Title: Neoadjuvant chemoradiation and pancreaticoduodenectomy for initially locally advanced head pancreatic adenocarcinoma

Authors: O. Turrini, F. Viret, L. Moureau, J. Guiramand, V. Moutardier, B. Lelong, M. Giovannini, J.R. Delpero

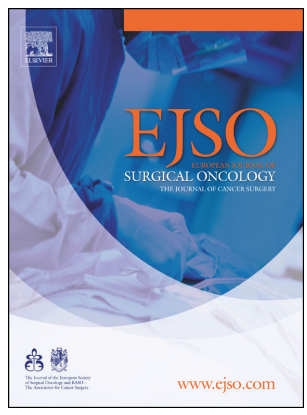

PII: S0748-7983(09)00196-6

DOI: 10.1016/j.ejso.2009.06.005

Reference: $\quad$ YEJSO 2849

To appear in: European Journal of Surgical Oncology

Received Date: 7 April 2009

Revised Date: 3 June 2009

Accepted Date: 8 June 2009

Please cite this article as: Turrini O, Viret F, Moureau L, Guiramand J, Moutardier V, Lelong B, Giovannini M, Delpero JR. Neoadjuvant chemoradiation and pancreaticoduodenectomy for initially locally advanced head pancreatic adenocarcinoma, European Journal of Surgical Oncology (2009), doi: 10.1016/j.ejso.2009.06.005

This is a PDF file of an unedited manuscript that has been accepted for publication. As a service to our customers we are providing this early version of the manuscript. The manuscript will undergo copyediting, typesetting, and review of the resulting proof before it is published in its final form. Please note that during the production process errors may be discovered which could affect the content, and all legal disclaimers that apply to the journal pertain. 
Original article

\title{
Neoadjuvant chemoradiation and pancreaticoduodenectomy for initially locally advanced head pancreatic adenocarcinoma
}

\author{
O. Turrini MD*, F. Viret MD** L. Moureau MD ${ }^{*}$ J. Guiramand MD*, V. Moutardier MD*, B. Lelong MD*, \\ M. Giovannini MD*** and J R. Delpero MD*
}

Departments of ${ }^{*}$ Surgical Oncology, ${ }^{* *}$ Medical Oncology, ${ }^{* * *}$ Endoscopy and ${ }^{\circ}$ Radiotherapy Institut Paoli-Calmettes and Université de la Méditerranée Marseille, France.

Corresponding author: Olivier Turrini

Institut Paoli-Calmettes

232 Bd de Sainte Marguerite

13009 Marseille, France.

Telephone number: $\quad 0491223660$

Fax number: $\quad 0491223550$

Email address: $\quad$ oturrini@yahoo.fr

turrinio@marseille.fnclcc.fr 


\begin{abstract}
BACKGROUND: The most accepted treatment for locally advanced pancreatic adenocarcinoma (LAPA) is chemoradiotherapy (CRT). We sought to determine the benefit of pancreaticoduodenectomy (PD) in patients with LAPA initially treated by neoadjuvant CRT.

METHODS: From J anuary 1996 to December 2006, 64 patients with LAPA (borderline, $n=49$; unresectable, $n=15$ ) received 5-fluorouracil-cisplatin-based CRT. Of the 64 patients, 47 had progressive disease at restaging. Laparotomy was performed for 17 patients, and PD was performed in 9 patients (resected group). Fifty-five patients had CRT followed by gemcitabine-based chemotherapy (unresected group).
\end{abstract}

RESULTS: The median survival and overall 5-years survival duration of all 64 patients were 14 months and $12 \%$, respectively. The mean delay between diagnosis and surgical resection was 5.5 months. Mortality and morbidity from PD were $0 \%$ and $33 \%$, respectively. The median survival of the resected group versus the unresected group was 24 months vs. 13 months. Three specimens presented a major pathological response at histological examination. No involved margins were found and positive lymph nodes were found in one patient. Resected patients developed distant metastases. CONCLUSIONS: PD after CRT was safe and resected patients had interesting survival rates. However, resected patients developed metastatic disease and new neoadjuvant regimens are needed to improve the survival of these patients.

Key words: pancreatic adenocarcinoma, locally advanced, neoadjuvant, chemoradiation 


\section{Introduction}

Resection and perioperative treatment for patients with resectable pancreatic adenocarcinoma has improved survival over the last two decades but overall patient survival remains poor ${ }^{1,2}$. At the time of diagnosis, tumors are classified according to radiological findings: the improvement of helical dual phase scanning sensitivity and surgeons' experience has advanced the classification from resectable and unresectable to resectable, borderline and unresectable ${ }^{3,4}$. Locally advanced pancreatic adenocarcinoma (LAPA), comprising both borderline and unresectable tumors, is characterized by the abutment or invasion of major vascular structures preventing surgeons from achieving optimal R0 resection. Thus, patients diagnosed with LAPA are likely to be spared from surgery; rapid disease progression and poor clinical status means patients undergo exclusively medical treatment with poor survival rates ${ }^{5,6}$. However, patients diagnosed with non-metastatic LAPA with a good clinical status are likely to undergo chemoradiation $(\mathrm{CRT})^{7}$. Although it is impossible for patients with arterial adhesion/invasion to undergo resection, venous involvement proved not to be a contraindication to resection ${ }^{8-13}$. Thus, despite low resection rates, several reports showed interesting results on overall survival ${ }^{14-20}$ after pancreaticoduodenectomy (PD) for LAPA. Moreover, not resecting the tumor exposed patients to recurrent biliary and digestive obstruction, increasing the incidence of uncontrollable pain and a poor quality of life ${ }^{21}$. In 1996, we started a neoadjuvant approach for pancreatic adenocarcinoma and we sought to determine the impact of PD after CRT in patients initially diagnosed with LAPA. 


\section{Methods}

\section{Patient selection}

Between J anuary 1996 and December 2006, 151 patients were diagnosed with a histologically proven non-metastatic adenocarcinoma of the pancreatic head and were considered eligible for neoadjuvant CRT. Pancreatic cancer was staged by physical examination, chest radiography, biopsy (fine needle aspiration with Wilson-Cook 22 gauge, $8 \mathrm{~cm}$ needles) obtained by endoscopy under ultrasound guidance (EUS) (Pentax-Hitachi, Hamburg, Germany), and thin-section contrastenhanced helical dual phase scanning (CT scan). Patients with adenocarcinoma of the tail or neck of the pancreas, intraductal papillary mucinous adenocarcinoma, tumors of neuroendocrine origin or with carcinoma of the duodenum, distal common bile duct, or ampulla of Vater were excluded from this study. Patients having any major comorbidity precluding consideration of pancreatic surgery were also excluded. Resectability was assessed by both surgeons and radiologists and tumors were classified as resectable $(n=87)$, borderline $(n=49)$ and unresectable $(n=15)$ (table 1$)$. Biliary stenting by a 10-French plastic stent was performed before or during neoadjuvant CRT if any sign of cholangitis or complete biliary obstruction occurred.

\section{Primary treatment and restaging $(n=64)$}

Neoadjuvant CRT consisted of standard-fractionation radiotherapy (45 Gy for 5 weeks) combined with concurrent chemotherapy, including continuous infusion of 5-fluorouracil $\left(650 \mathrm{mg} / \mathrm{m}^{2}\right.$ on Days $1-5$ and Days $21-25$ ) accompanied by a cisplatin bolus ( $80 \mathrm{mg} / \mathrm{d} / \mathrm{m}^{2}$ on Days 2 and 22 ). World Health Organization (WHO) Grades 2, 3 or 4 toxicity events were recorded during CRT and 4 patients (6\%) experienced grade 3 toxicity. All patients were restaged after completion of chemoradiation and radiologic tumor response was determined using Response Evaluation Criteria In Solid Tumors (RECIT) criteria for staging. Forty six patients had progressive disease (metastases, $n=25$; increase in gross tumor size, $n=12$; carcinomatosis, $n=9$. The serum level of $C A 19-9$ was not retained to spare patients from explorative laparotomy if no distant metastasis was detected at restaging. The laparoscopic approach was routinely performed and one patient was identified with carcinomatosis.

\section{Explorative laparotomy $(n=17)$}


Laparoscopic evaluation of vascular involvement using echolaparoscopy was not used routinely because: a) CRT and/or the presence of metallic biliary stents made it difficult to achieve an appropriate analysis of the tumor boundaries, b) endosonographic encasement did not allow for diagnosis of the real features of the involvement (post-radic or tumoral), and c) biopsy under echolaparoscopy of perivascular tissue was hazardous if needed. During laparotomy, 4 explorative steps were always carried out. Step one: careful examination of the entire abdomen using a laparoscopic approach. Step two: dissection of the superior mesenteric artery (SMA) on its left side, pulling down the duodenojejunal angle. The SMA was then completely dissected on both face and multiples biopsies were performed to prevent any tumoral adhesion and $R 1 / R 2$ resection. This allowed for a complete lymph node resection if required (SMA lymphadenectomy). Step tree: dissection of the inferior side of the pancreas, including entire dissection of the portal vein (PV) and the superior mesenteric portal vein (SMPV) confluent. Step four: dissection of the upper side of the pancreas to identify encasement of the hepatic artery (HA) or celiac trunk $\mathrm{CT}$. This allowed for the complete resection of the lymph nodes of the corresponding area. Multiple perivascular biopsies were routinely performed to distinguish post-radic tissue with tumor involvement. No false positive or negative results were noted after frozen section analyses. Patients underwent a resection with the intention of a cure if the biopsies were negative.

\section{Resection ( $n=9)$}

Nine patients (resected group) had a PD with extended lymphadenectomy. Two patients needed an enlarged resection adjacent to nearby organs (right colon, $n=2$ ). We routinely performed staining of the pancreatic section, posterior margin and PV bed margin in the operating room. Pathological examination included the margin status, lymph node involvement, gross tumor size and perineural invasion. The absence of residual cancer in the resected specimen (sterilized specimen) after CRT was defined as a complete pathological response (урT0). Minimal residual disease was defined by presence of tumor $<2 \mathrm{~mm}$ in the resected specimen. No resected patients had adjuvant chemotherapy. Fifty-five patients (unresected group) had CRT followed by systemic gemcitabinebased chemotherapy for an unresectable tumor.

\section{Follow-up and statistical analysis}


All living patients were evaluated by a combined medical and surgical team at 1, 4 and 6 months postoperatively, and every year thereafter. Physical examination, thin-section contrast-enhanced helical dual phase CT scan and tumor markers (CEA, CA 19-9) were routinely obtained in follow-up. The type of recurrence was noted (metastasis, carcinomatosis or local recurrences). Survival was measured from the date of diagnosis to the date of death or J anuary 1,2008 , the censor date. Survival was examined using the Kaplan-Meier method. Statistical comparisons were conducted using log rank tests; $p<0.05$ was considered to be statistically significant. 


\section{Results}

\section{Entire population, restaging $(n=64)$}

No patients were lost to follow-up, with a mean follow-up of 38 months (range 12-117). Overall 1, 3 and 5 years survival of all 64 patients who underwent primary treatment and restaging were $58 \%, 12 \%$ and $12 \%$, respectively; the median overall survival was 14 months. The mean delay between diagnosis and surgical resection was 5.5 months (range 3-8). In patients without distant disease found at restaging $(n=34)$, local tumor progression was documented in 12 patients, stable disease was documented in 16 patients, and partial remission was documented in one patient.

\section{Patients who underwent explorative laparotomy $(n=17)$ and resected patients $(n=9)$}

The characteristics of patients having an explorative laparotomy are summarized in Table 2. Pathological findings and outcomes of resected patients $(n=9)$ are summarized in Table 3. Mortality and morbidity were $0 \%$ and $33 \%$ (gastric emptying, $n=2$; pancreatic fistula, $n=1$ ), respectively. Overall 1 and 3 years survival rates of the resected group versus the unresected group were $78 \%$ vs. $53 \%(p=0.04)$ and $65 \%$ vs. $3 \%(p<0.01)$, respectively. The median survival of the resected group vs. the unresected group was 24 months vs. 13 months (figure 1), respectively.

\section{Pathological findings (table 3)}

Three patients had a sterilized (yрт0, n=1) or minimal residual disease $(n=2)$ at histological examination. No involved margins were found. Positive lymph nodes were found in 1 patient.

\section{Recurrences (table 3)}

Four patients of the resected group developed distant metastatic recurrence. Four patients were alive without recurrence with a mean follow up of 32 months. One patient died of another cause (myocardial infarction) than pancreatic cancer during follow up. 


\section{Discussion}

Using strict CT-scan criteria to evaluate LAPA, complete resection was achieved in only $14 \%$ of patients. However, the overall survival time seemed to be improved due to the local effect of CRT (no margin involved, downstaging of tumors) and time-selection sparing patients with progressive disease.

\section{Resection rate}

Resection rates vary from $13 \%$ to $63 \%$ in the literature (table 4) due to a) CT-scan and endoscopic criteria chosen to define LAPA and/or b) the fact that studies focus on borderline tumors. Arterial involvement remains a contraindication for resection due to the high morbidity involved and low benefit gained with regards to survival. On the other hand, several reports ${ }^{8-13}$ showed that resection/reconstruction of the PV or SMPV confluent were safe and improved survival. Therefore, tumors in contact with major venous vasculature without circumferential encasement, PV thrombosis or large involvement of the SMPV confluent must be considered resectable tumors. Those findings help to optimize the resectability classification: pancreatic head adenocarcinoma could be staged as resectable, borderline or unresectable. However, the total encasement of the SMA or CT (previously an unresectable tumor) was associated with a poor resection rate compared to a case of tumor abutment (previously classified as a borderline tumor) ( $7 \%$ versus $16 \%$, respectively).

\section{Survival}

The median survival of patients with LAPA was poor (14 months) as reported in table 4. However, patients with LAPA who underwent curative PD had comparable median survival times than patients with initially resectable tumors ${ }^{22}$. However, there were two major criticisms of our study. Firstly, the mean delay between diagnosis and surgery was over 5 months, higher than we reported ${ }^{23}$ for patients with initially resectable tumors. In the early experience of the series, the persistence of periarterial thickness at restaging was concerning and patients underwent a supplementary observation time before undergoing a laparotomy. In 2005, Sa Cuhna et al ${ }^{24}$ showed that the thickness around SMA or celiac axis could be treated by CRT and did not preclude a laparotomy. Thus, we scheduled surgery 5 weeks after completion of CRT, as for neoadjuvant CRT for resectable tumors. We supposed that our additional time-selection of CRT participated to spare patients with disease progression and identified good candidates for surgery. Secondly, the small number of patients in the resected group precluded from emphatic conclusions. Nevertheless, our findings seem to be comparable to other series and we found that patients who underwent PD for LAPA did have an improved survival time. 


\section{Future strategies}

CRT associated with PD enabled the optimal local control of the disease, as confirmed by tumor downstaging (one patient with ypT0 stage tumor and 2 patients with minimal residual disease), margin free resections and no identified local recurrences ${ }^{25-28}$. However, outstanding local control did not prevent distant recurrences and 4 resected patients experienced metastatic spread. On the other hand, $53 \%$ of patients with initially diagnosed localized disease developed metastasis during CRT and consequently underwent inappropriate local treatment. We strongly advocate that systemic chemotherapy should be used in the management of patients diagnosed with apparently nonmetastatic LAPA. We suggest that a neoadjuvant approach should be preferred and should include gemcitabine-based chemotherapy and radiation therapy. This makes sense, particularly since delayed recovery after surgery precludes adjuvant therapy in approximately $30 \%$ of patients who undergo elective PD as the initial treatment for pancreatic adenocarcinoma ${ }^{29,30}$. However, the best neoadjuvant regimen is still to be determined ${ }^{31}$. Recently, new neoadjuvant strategies have shown interesting results in resectable and locally advanced pancreatic cancer ${ }^{32}$. However, further studies are needed to determine the impact on the postoperative course and overall survival in resected patients with initially diagnosed LAPA.

\section{Conclusions}

Patients with pancreatic cancer should be discussed within a multidisciplinary staff setting to determine tumor resectability and decide on appropriate neoadjuvant treatment (drugs, doses, sequences and so on). Patients who underwent curative resection had comparable survival to patients with an initially resectable tumor. Thus, despite low resection rates, the opportunity for curative resection should not be refuted based on a CT-scan assessment. While waiting for more effective therapies besides gemcitabine and 5-FU, new neoadjuvant regimens have to be assessed in order to increase arguments for surgery as a last approach.

\section{Conflict of interest}

The authors declare that they have no conflict of interest. 


\section{References}

1. Oettle H, Post S, Neuhaus P, Gellert K, Langrehr J, Ridwelski K, Schramm H, Fahlke J, Zuelke C, Burkart C, Gutberlet K, Kettner E, Schmalenberg H, Weigang-Koehler K, Bechstein WO, Niedergethmann M, Schmidt-Wolf I, Roll L, Doerken B, Riess H. Adjuvant chemotherapy with gemcitabine vs observation in patients undergoing curative-intent resection of pancreatic cancer: a randomized controlled trial. J AMA. 2007 J an 17;297(3):267-77.

2. Evans DB, For The Multidisciplinary Pancreatic Cancer Study Group. R esectable pancreatic cancer: The role for neoadjuvant/preoperative therapy.HPB (Oxford). 2006;8(5):365-8.).

3. Varadhachary DR, Tamm EP, Abruzzese J L, Xiong HQ, Crane CH, Wang H, Lee J E, P isters PW, Evans DB, Wolff RA. Borderline resectable pancreatic cancer : definitions, management and role of preoperative therapy. Ann Surg Oncol. 2006, $13: 1035-46$

4. Katz MH, Pisters PW, Evans DB, Sun CC, Lee J E, Fleming J B, Vauthey J N, Abdalla EK, Crane $\mathrm{CH}$, Wolff RA, Varadhachary GR, Hwang RF. Borderline resectable pancreatic cancer: the importance of this emerging stage of disease. J Am Coll Surg. 2008 May;206(5):833-46

5. Sultana A, S mith CT, Cunningham D, Starling N, Neoptolemos J P, G haneh P.J Meta-analyses of chemotherapy for locally advanced and metastatic pancreatic cancer. Clin Oncol. 2007 J un 20;25(18):2607-15

6. Haddock MG, Swaminathan R, Foster NR, Hauge MD, Martenson J A, Camoriano J K, Stella PJ, Tenglin RC, Schaefer PL, Moore DF J r, Alberts SR. Gemcitabine, cisplatin, and radiotherapy for patients with locally advanced pancreatic adenocarcinoma: results of the North Central Cancer Treatment Group P hase II Study N9942.. J C lin Oncol. 2007 J un 20;25(18):2567-72).

7. White RR, Reddy S, Tyler DS. The role of chemoradiation therapy in locally advanced pancreatic cancer. HPB (Oxford). 2005;7(2):109-13.

8. Ishikawa O, Ohigashi H, Imaoka S, Furukawa H, Sasaki Y, Fujita M, Kuroda C, Iwanaga T. Preoperative indications for extended pancreatectomy for locally advanced pancreas cancer involving the portal vein. Ann Surg. 1992, $215: 231-236$

9. Sasson AR, Hoffman J P, Ross EA, Kagan SA, Pingpank J F, E isenberg BL. En bloc resection for locally advanced cancer of the pancreas: is it worthwhile? J Gastrointest Surg. 2002, 6 : 147-158

10. Tseng J F, Raut CP, Lee JE, Pisters PW, Vauthey J N, Abdalla EK, Gomez HF, Sun CC, Crane CH, Wolff RA, Evans DB. Pancreaticoduodenectomy with vascular resection: Margin status and survival duration. J Gastrointest Surg 2004, $8: 935-950$

11. Fuhrman GM, Leach SD, Staley CA, Cusack J C, Charnsangavej C, Cleary KR, El-Naggar AK, Fenoglio CJ , Lee J E, Evans DB. Rationale for en bloc vein resection in the treatment of pancreatic adenocarcinoma adherent to the superior mesenteric-portal vein confluence. Pancreatic Tumor 
Study Group. Ann Surg. 1996, 223 : 154-16

12. Carrere N, Sauvanet A, Goere D, Kianmanesh R, Vullierme MP, Couvelard A, Ruszniewski P, Belghiti J . Pancreaticoduodenectomy with mesentericoportal vein resection for adenocarcinoma of the pancreatic head. World J Surg. 2006 Aug;30(8):1526-35.

13. Wang C, Wu H, Xiong J, Zhou F, Tao J, Liu T, Zhao G, Gou S. Pancreaticoduodenectomy with vascular resection for local advanced pancreatic head cancer: a single center retrospective study. J Gastrointest Surg. 2008 Dec;12(12):2183-90..

14. Wanebo HJ, Glicksman AS, Vezeridis MP, Clark J, Tibbetts L, Koness RJ, Levy A. Preoperative Chemotherapy, R adiotherapy, and Surgical Resection of Locally Advanced Pancreatic Cancer. Arch. Surg. 2000; 135: 81-87

15. Mehta VK, Fisher G, Ford J A, P oen J C, Vierra MA, O berhelman H, Niederhuber J , Bastidas J A. Preoperative chemoradiation for marginally resectable adenocarcinoma of the pancreas. J Gastrointest Surg 2001, $5: 27-35$.

16. Ammori J B, Colleti LM, Zalupski MM, Eckhauser FE, Greenson J K, Dimick J, Lawrence TS, McGinn CJ . Surgical resection following radiation therapy with concurrent gemcitabine in patients with previously unresectable adenocarcinoma of the pancreas. J ournal of Gastrointestinal Surgery $2003,7,768-772$.

17. Aristu J , Canon R, Pardo F, Martínez-Monge R, Martin-Algarra S, Manuel Ordoñez J, Villafranca E, Moreno M, Cambeiro M, Azinovic I. Surgical resection after preoperative chemoradiotherapy benefits selected patients with unresectable pancreatic cancer. Am J C lin Oncol 2003, 26 :30-36

18. Massucco P, Capussotti L, Magnino A, Sperti E, Gatti M, Muratore A, Sgotto E, Gabriele P, Aglietta M. Locally advanced pancreatic resections after chemoradiotherapy for locally advanced ductal adenocarcinoma: analysis of perioperative outcome and survival. Ann Surg Oncol. 2006 Sep;13(9):1201-8.

19. Lind PA, Isaksson B, Almström M, J ohnsson A, Albiin N, Byström P, Permert J. E fficacy of preoperative radiochemotherapy in patients with locally advanced pancreatic carcinoma. Acta Oncol. 2008;47(3):413-20.

20. Katz MH, P isters PW, Evans DB, Sun CC, Lee J E, Fleming J B, Vauthey J N, Abdalla EK, Crane $\mathrm{CH}$, Wolff RA, Varadhachary GR, Hwang RF. Borderline resectable pancreatic cancer: the importance of this emerging stage of disease. J Am Coll Surg. 2008 May;206(5):833-46;

21. Crippa S, Domínguez I, Rodríguez J R, Razo O, Thayer SP, Ryan DP, Warshaw AL, Fernándezdel Castillo C. Quality of life in pancreatic cancer: analysis by stage and treatment. J Gastrointest Surg. 2008 May;12(5):783-93;

22. Stessin AM, Meyer J E, Sherr DL. Neoadjuvant radiation is associated with improved survival in 
patients with resectable pancreatic cancer: an analysis of data from the surveillance, epidemiology, and end results (SEER) registry. Int J Radiat Oncol Biol Phys. 2008 Nov $15 ; 72(4): 1128-33$.

23. Moutardier V, Turrini O, Huiart L, Viret F, Giovannini MH, Magnin V, Lelong B, Bories $E$, Guiramand J , Sannini A, Giovannini M, Houvenaeghel G, Blache J L, Moutardier J C, Delpero J R A reappraisal of preoperative chemoradiation for localized pancreatic head ductal adenocarcinoma in a 5-year single-institution experience. .J Gastrointest Surg. 2004 May-J un;8(4):502-10.

24. Sa Cunha A, Rault A, Laurent $C$, Adhoute $X$, Vendrely V, Béllannée $G$, Brunet $R$, Collet D, Masson B. Surgical resection after radiochemotherapy in patients with unresectable adenocarcinoma of the pancreas. J Am Coll Surg 2005, $201: 359-65$

25. Ishikawa O, Ohhigashi H, Teshima $T$, Chatani M, Inoue T, Tanaka S, Kitamura T, Wada A, Sasaki Y, Imaoka S. Clinical and histopathological appraisal of preoperative irradiation for adenocarcinoma of the pancreatoduodenal region. J Surg Oncol 1989, $40: 143-151$

26. Kim HJ , Czischke K, Brennan MF, Conlon KC. Does Neoadjuvant Chemoradiation Downstage Locally Advanced Pancreatic Cancer? J ournal of Gastrointestinal Surgery 2002, 6 : 763-769

27. Sasson AR, Wetherington RW, Hoffman J P, Ross EA, Cooper H, Meropol NJ , Freedman G, Pingpank J F, Eisenberg BL. Neoadjuvant chemoradiotherapy for adenocarcinoma of the pancreas: Analysis of histopathology and outcome. Int J Gastrointest Cancer 2003, 34 : 121-128

28. White RR, Xie HB, Gottfried MR, Czito BG, Hurwitz HI, Morse MA, Blobe GC, Paulson EK, Baillie J, Branch MS, J owell PS, Clary BM, Pappas TN, Tyler DS. Significance of histological response to preoperative chemoradiotherapy for pancreatic cancer Ann Surg Oncol. 2005, 12 : 214-21

29. Aloia TA, Lee J E, Vauthey J N, Abdalla EK, Wolff RA, Varadhachary GR, Abbruzzese J L, Crane $\mathrm{CH}, \mathrm{E}$ vans $\mathrm{DB}, \mathrm{P}$ isters PW.. Delayed recovery after pancreaticoduodenectomy: a major factor impairing the delivery of adjuvant therapy? J Am Coll Surg. 2007 Mar;204(3):347-55.

30. Snady H, Bruckner H, Cooperman A, Paradiso J, Kiefer L. Survival advantage of combined chemoradiotherapy compared with resection as the initial treatment of patients with regional pancreatic carcinoma. An outcomes trial. Cancer. 2000 J ul 15;89(2):314-27.

31. Kim R, Saif MW. Is there an optimal neoadjuvant therapy for locally advanced pancreatic cancer? J OP. 2007 May 9;8(3):279-88. Review.

32. Moureau-Zabotto L, Phélip J M, Afchain P, Mineur L, André T, Vendrely V, Lledo G, Dupuis 0 , Huguet F, Touboul E, Balosso J, Louvet C. Concomitant administration of weekly oxaliplatin, fluorouracil continuous infusion, and radiotherapy after 2 months of gemcitabine and oxaliplatin induction in patients with locally advanced pancreatic cancer: a Groupe Coordinateur Multidisciplinaire en Oncologie phase II study. J Clin Oncol. 2008 Mar 1;26(7):1080-5. 
Table 2: characteristics of patients who underwent explorative laparotomy $(n=17)$.

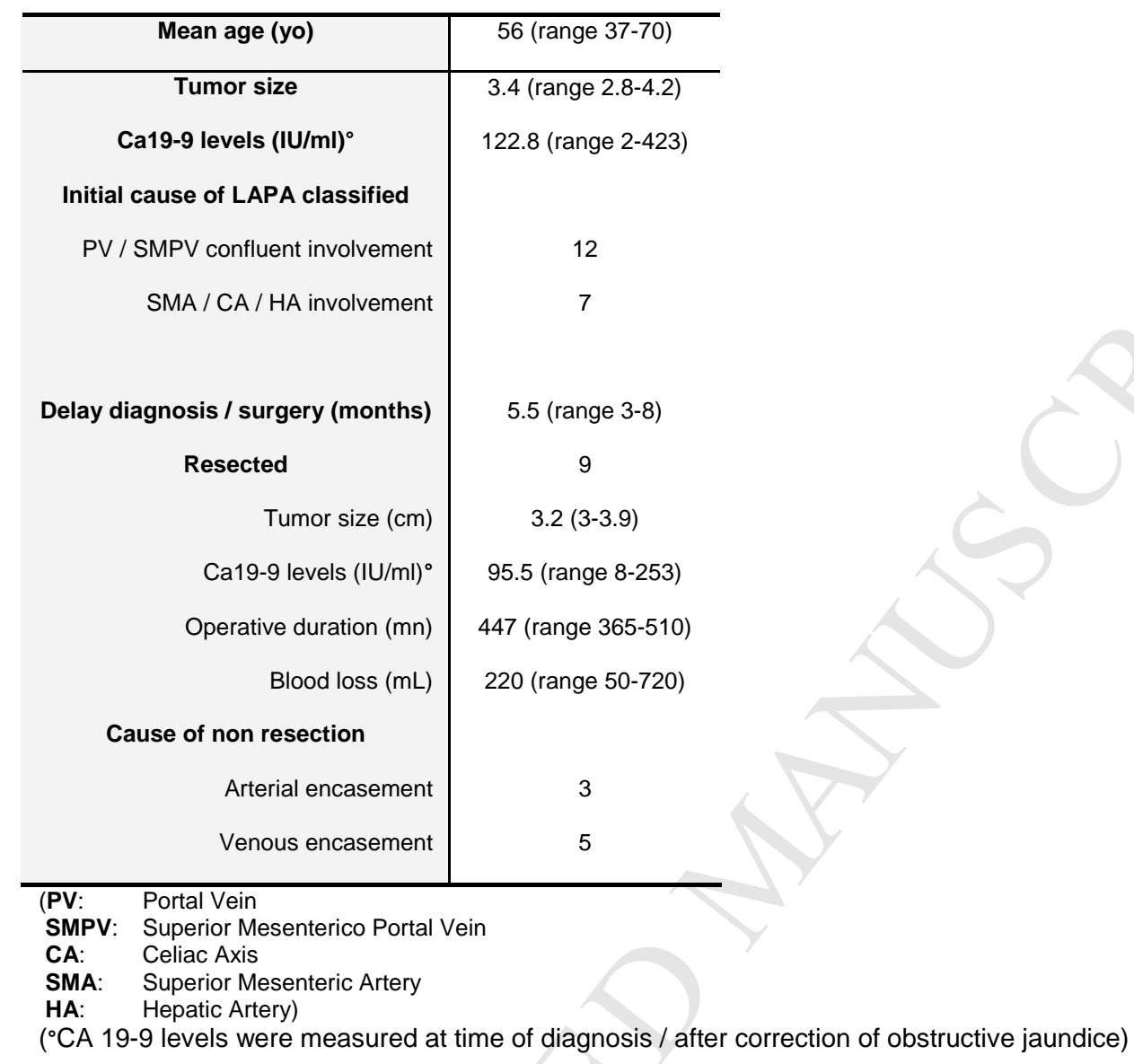


Table 3: characteristics of patients with LAPA who underwent pancreaticoduodenectomy.

\begin{tabular}{|c|c|c|c|c|c|c|c|c|c|c|}
\hline \multicolumn{2}{|r|}{ Patient } & 1 & 2 & 3 & 4 & 5 & 6 & 7 & 8 & 9 \\
\hline & Age & 63 & 56 & 68 & 59 & 59 & 58 & 43 & 59 & 67 \\
\hline & essel involved & PV & PV & CA & $\mathrm{PV}+\mathrm{SMA}$ & PV & PV & $\mathrm{SMA}+\mathrm{CA}$ & $\mathrm{PV}+\mathrm{SMA}$ & PV \\
\hline Delay & to surgery (months) & 3 & 5 & 7 & 3 & 6 & 5 & 8 & 5 & 8 \\
\hline CA 1 & $9-9$ levels (IU/ml) & 15 & 110 & 253 & 185 & 8 & 29 & 139 & 14 & 89 \\
\hline $\mathrm{Va}$ & scular resection & L.PV & L. PV & no & no & T. PV & no & no & L. PV & L.PV \\
\hline Oper & ative duration (mn) & 421 & 382 & 365 & 485 & 510 & 390 & 505 & 490 & 475 \\
\hline & lood loss (ml) & 150 & 120 & 50 & 380 & 720 & 120 & 80 & 210 & 160 \\
\hline & pecimen status & - & - & - & - & - & MRD & MRD & & Sterilized \\
\hline Nod & es (positive/total) & $0 / 11$ & $0 / 9$ & $0 / 17$ & $0 / 6$ & $1 / 5$ & $0 / 18$ & $0 / 5$ & $0 / 7$ & $0 / 10$ \\
\hline & sitives margins & no & no & no & no & no & no & no & no & no \\
\hline Per & ineural invasion & no & yes & yes & yes & yes & no & no & yes & no \\
\hline & Recurrence & $-*$ & Meta.* & - & Meta.* & - & & Meta.* & Meta. & - \\
\hline & Morbidity & no & no & $\mathrm{PF}$ & no & no & GE & no & GE & no \\
\hline & rvival (months) & 4 & 12 & - & 13 & & - & 27 & - & - \\
\hline $\begin{array}{l}\text { (PV: } \\
\text { CA: } \\
\text { SMA: } \\
\text { L. PV: } \\
\text { T. PV: } \\
\text { MRD: } \\
\text { PF: } \\
\text { GE: } \\
{ }^{*}: \\
\text { ( }^{\circ} \text { CA } 1 .\end{array}$ & $\begin{array}{l}\text { Portal Vein; } \\
\text { Celiac Axis } \\
\text { Superior Mesenteric } \\
\text { Lateral resection of } \\
\text { Troncular resection } \\
\text { Minimal Residual Di } \\
\text { Pancreatic Fistula } \\
\text { Gastric Emprtying } \\
\text { patient dead) } \\
\text { 9-9 levels were mea }\end{array}$ & $\begin{array}{l}\text { Artery } \\
\text { oortal vei } \\
\text { of portal } \\
\text { sease }\end{array}$ & jein & 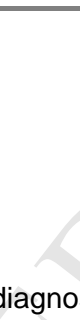 & $10 \mathrm{ft}$ & & & & & \\
\hline
\end{tabular}


Table 4: patients receiving neoadjuvant CRT for LAPA.

\begin{tabular}{|c|c|c|c|c|c|c|}
\hline & year & $\mathbf{n}$ & Chemo. & Resection rate & $\begin{array}{l}\text { Median survival } \\
\text { resected } \\
\text { (months) }\end{array}$ & $\begin{array}{l}\text { Median survival } \\
\text { unresected } \\
\text { (months) }\end{array}$ \\
\hline${ }^{*}$ Wanebo et al. ${ }^{14}$ & 2000 & 14 & $5 \mathrm{FU} /$ cisplat & $63 \%$ & 19 & - \\
\hline${ }^{*}$ Mehta et al. ${ }^{15}$ & 2001 & 15 & $5 \mathrm{FU}$ & $60 \%$ & 30 & 8 \\
\hline Ammori et al. ${ }^{16}$ & 2003 & 67 & Gem & $13 \%$ & 17.6 & 11.9 \\
\hline Aristu et al. ${ }^{17}$ & 2003 & 47 & $5 \mathrm{FU} /$ cisplat & $19 \%$ & 23 & 10 \\
\hline Massuco et al. ${ }^{18}$ & 2006 & 23 & Gem & $26 \%$ & 20 & 12 \\
\hline Lind et al. ${ }^{19}$ & 2006 & 17 & Ox/cap & $47 \%$ & 29 & - \\
\hline${ }^{*}$ Katz et al. ${ }^{20}$ & 2008 & 160 & Gem & $41 \%$ & 40 & 13 \\
\hline Current series & 2008 & 64 & $5 \mathrm{FU} /$ cisplat & $14 \%$ & 24 & 13 \\
\hline
\end{tabular}

(*borderline series; Gem: gemcitabine-based chemoradiation; cisplat: cisplatin-based chemoradiation; ox: oxaliplatin; cap: capecitabine) 
Table 1: allocation of patients with locally advanced pancreatic adenocarcinoma according to radiological findings.

\begin{tabular}{ccc}
\hline & Borderline $(\mathbf{n = 4 9 )}$ & Unresectable $(\mathbf{n}=\mathbf{1 5})$ \\
\hline SMA & Tumor abutment $\leq 180^{\circ}$ of the circumference & Encased $>180^{\circ}$ \\
CT I HA & Short segment encasement / abutment & Encased with extension to the CA origin \\
SMV I PV & Short segment occlusion & Occluded and no technical option for \\
& & reconstruction
\end{tabular}

(SMA: Superior Mesenteric Artery; CT: celiac trunk; HA: Hepatic Artery; SMV: Superior Mesenteric Vein; PV: Portal

Vein) 
Figure 1: overall survival of patients with Locally Advanced Pancreatic Adenocarcinoma (LAPA).

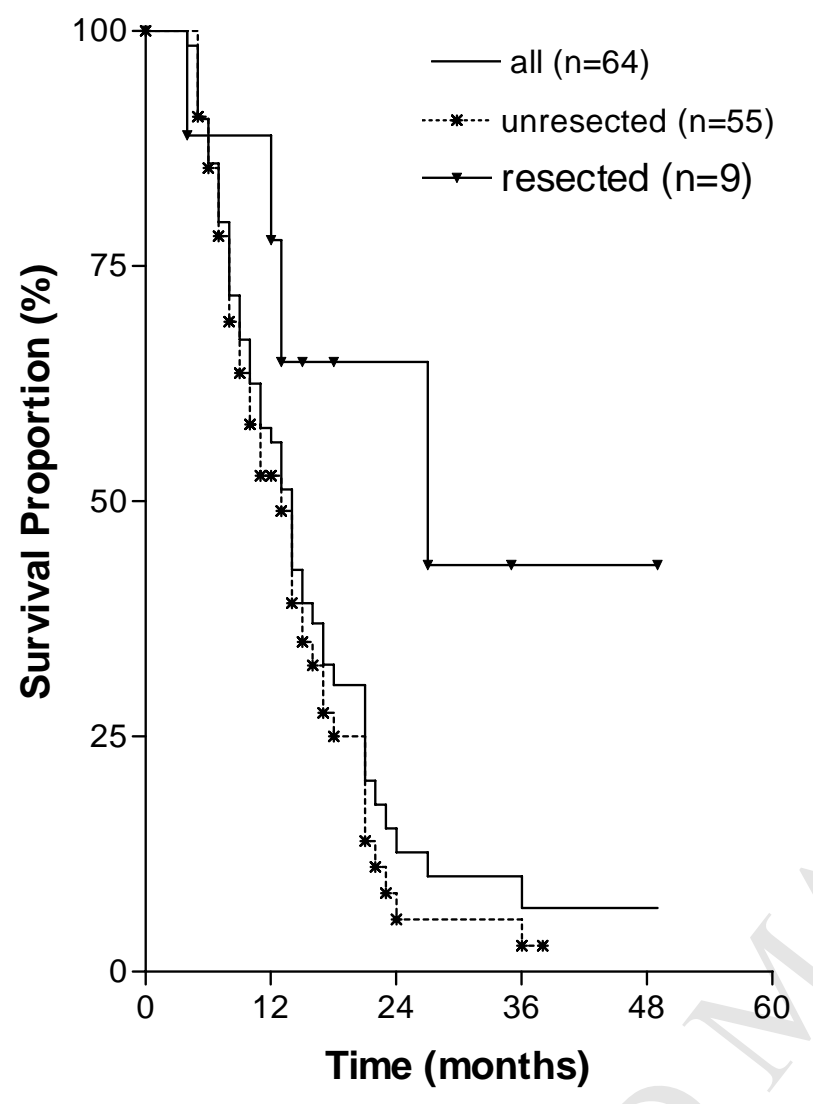

$\underline{\text { Log -rank test unresected vs. resected }}=0.01$

$\frac{\text { Subjects at risk }}{0}$

all patients 64 unresected 55 resected
12

37

29

8
24

6

3

4
36

3

2
48

2

1 